\title{
Niche heterogeneity in the bone marrow
}

\author{
Alexander Birbrair ${ }^{1,2}$ and Paul S. Frenette ${ }^{1,2}$ \\ ${ }^{1}$ Ruth L. and David S. Gottesman Institute for Stem Cell and Regenerative Medicine Research, \\ Albert Einstein College of Medicine, Bronx, New York \\ ${ }^{2}$ Departments of Medicine and Cell Biology, Albert Einstein College of Medicine, Bronx, New York
}

\begin{abstract}
In adult mammals, hematopoietic stem cells (HSCs) are defined by their abilities to self-renew and to differentiate to form all blood cell lineages. These rare multipotent cells occupy specific locations in the bone marrow microenvironment. The specific microenvironment regulating HSCs, commonly referred to as the niche, comprises multiple cell types whose exact contributions are under active investigation. Understanding cellular cross talk involving HSCs in the bone marrow microenvironment is of fundamental importance for harnessing therapies against benign and malignant blood diseases. In this review, we summarize and evaluate recent advances in our understanding of niche heterogeneity and its influence on HSC function.
\end{abstract}

\section{Keywords}

BM; microenvironment; niche; stem cells

\section{Introduction}

Hematopoietic stem cells (HSCs) represent a rare subpopulation of hematopoietic cells, mostly residing in the bone marrow (BM) ${ }^{1,2}$ that reign at the top of the hematopoietic hierarchy. These cells are endowed with regulated quiescence ${ }^{3,4}$ and a capacity for longlived self-renewal that preserves the multipotency of mother cells and sustains the generation of all blood cell types throughout life. ${ }^{5-10}$ Their capacity to rebuild the entire adult hematopoietic system makes HSCs invaluable for the treatment of multiple hematopoietic disorders. For several decades, the therapeutic potential of HSCs has been applied to regenerate the hematopoietic system via BM transplantation procedures. ${ }^{11}$ Understanding the signaling mechanisms that determine HSC fate will be crucial for the success of clinical applications. Recent investigations using genetically modified mouse models suggest that decisions of HSC self-renewal and multilineage differentiation are dependent on the interaction with the surrounding microenvironment, also termed niche. ${ }^{12-14}$ Thus, proquiescence, prodifferentiation or pro-self-renewal microenvironments define HSC fate. ${ }^{15,16}$ Experimental evidence has shown that deregulation of those microenvironmental regulatory mechanisms plays a key pathogenic role in a variety of hematopoietic diseases. ${ }^{5}$

Address for correspondence: Paul S. Frenette MD, Albert Einstein College of Medicine, Michael F. Price Center, 1301 Morris Park Avenue, Room 101, Bronx, NY 10461. paul.frenette@einstein.yu.edu. 
In recent years, several cell types have been identified as potential niche-supporting cells for HSCs, regulating HSC activity by supplying various cytokines and retention factors. Here, we present an overview of the current knowledge on the variety of BM cell types and their effects on HSCs.

\section{Heterogeneity of HSCs and niches}

HSCs represent a functionally heterogeneous cell population in their degree of selfrenewal, ${ }^{17,18}$ life span, ${ }^{19-21}$ and differentiation capabilities. ${ }^{22}$ Self-renewal heterogeneity is manifested by distinct capacities of long-term (LT-HSC), intermediate-term (IT-HSC), and short-term repopulating HSCs (ST-HSC), ${ }^{23}$ which have been distinguished by differential abilities to engraft in vivo into irradiated hosts and to maintain multilineage hematopoiesis for extended time periods and/or by serial transplantation. ${ }^{24} \mathrm{~A}$ separate challenge for isolating HSC subpopulations is that they may represent a continuum of states of the same cell, which may be challenging to isolate, although a few markers have been shown to define distinct properties, such as CD150 for LT-HSCs, ${ }^{25,26}$ integrin a 2 (CD49b) for IT-HSCs, ${ }^{27}$ or platelet integrin CD41 (also known as Itga2b) for myeloid-biased adult HSCs. ${ }^{28}$

Single purified HSCs exhibit large fluctuations in their contributions to myeloid and lymphoid lineages. ${ }^{19}$ Subsequent studies demonstrated distinct biases of HSCs, with consistent preponderance to generate lymphoid or myeloid cells. ${ }^{29-31}$ Interestingly, on the basis of Hoechst dye-efflux capability, myeloid- and lymphoid-biased HSC subsets differ in their responsiveness to TGF- $ß 1$. This cytokine induces proliferation of myeloid-biased HSCs while inhibiting proliferation of lymphoid-biased HSCs. ${ }^{32}$ More recently, a platelet-biased HSC subset was identified through the use of a von Willebrand factor (vWF)-EGFP mouse system. ${ }^{33}$ High expression of $\mathrm{vWF}$, a blood glycoprotein mediating platelet aggregation, was reported in HSC-enriched BM cells. ${ }^{26}$ Transplantation of vWF-EGFP ${ }^{+}$and vWF-EGFP ${ }^{-}$ cells from the $\mathrm{CD} 150^{+} \mathrm{CD} 48^{-} \mathrm{CD} 34^{-} \mathrm{KSL}$ fraction of adult $\mathrm{BM}$ achieved long-term hematopoietic reconstitution in recipient mice. This study also suggested that $\mathrm{vWF}^{+} \mathrm{HSCs}$ are primed toward the megakaryocytic lineage. ${ }^{33}$

Very little is known about the extrinsic regulation of HSC subpopulations. For instance, it is unclear whether the niches for lymphoid-, myeloid-, or megakaryocyte-biased HSCs differ. The functional heterogeneity of HSCs points to the potential for matching heterogeneity in the microenvironmental influences that support the function and behavior of these HSC subsets. The reader is referred to excellent reviews that discuss these HSC subsets in detail. ${ }^{34-36}$ The remainder of the review will focus on niche heterogeneity.

The anatomy of the BM may shed light on the specific microenvironments where HSCs may reside and are regulated. BM is found within the central cavities of long and axial bones. The trabecular regions of the metaphysis have been shown to be the preferred site of HSC homing compared to the epiphysis or diaphysis. ${ }^{37}$ The inner surface of the bone cavities is covered by an endosteal lining consisting of osteoblasts, osteoclasts, and a single layer of flat bone-lining cells supported by a thin layer of reticular connective tissue. The endosteal region may present a greater concentration of free calcium ions from continuous bone remodeling. ${ }^{38,39}$ Several studies have noted that HSCs tend to localize peripherally near the 
bone surface rather than in the central medullary regions. ${ }^{38,40,41}$ Moreover, it has been suggested that HSCs at the endosteal location have greater self-renewal capacity than those in the central marrow cavity, ${ }^{42}$ suggesting the presence of a distinct microenvironment in this region. However, other recent analyses have suggested that HSCs may be randomly distributed in the BM. ${ }^{43}$ Interestingly, aged HSCs localize to sites further away from the endosteum compared with young $\mathrm{HSCs},{ }^{44}$ suggesting that $\mathrm{HSC}$ location is affected by aging.

The BM is served by numerous blood vessels of various sizes entering it through the cortical bone via nutrient canals. ${ }^{45}$ Lymphatic drainage is absent in the BM. ${ }^{46}$ The blood supplies of the bone and BM are interconnected through an endosteal network of vessels. Arteries give rise to a multitude of small, thin-walled arterioles that extend outwardly toward the cortical bone and sinusoids that pervade the central and endosteal marrow. Arterioles are small resistance vessels that, unlike other vessels in the BM, are wrapped circumferentially by one or more layers of smooth muscle cells. ${ }^{47,48}$ They are preferentially located close to the endosteal region of the BM. ${ }^{41}$ Nerve bundles follow the arterioles, with branches serving smooth muscle cells or terminating in the hematopoietic tissue among hematopoietic cells. ${ }^{49}$ The sinusoids form a permeable barrier for the passage of mature blood cells into the circulation. In contrast to arterioles, sinusoids are evenly distributed through the whole BM cavity and are not innervated. Both BM arteriolar and sinusoidal endothelial cells are surrounded by perivascular cells. ${ }^{50}$

Besides blood vessels and nerves, the BM tissue consists of a variety of cellular subtypes among hematopoietic and non-hematopoietic cells. Hematopoietic cells are most likely not randomly arranged but demonstrate a specific organization within the tissue. ${ }^{51}$ For instance, erythropoiesis takes place in distinct anatomical units (erythroblastic islands), ${ }^{52-54}$ and a subset of HSCs is located near megakaryocytes. ${ }^{55,56}$

A niche supporting HSCs identified in close proximity to blood vessels in the adult BM has been called the perivascular niche..$^{25,41}$ The perivascular niche itself is heterogeneous and contains distinct cell types. A recent study showed that dormant (quiescent) HSCs reside specifically in the proximity of arterioles rather than sinusoids, proposing that there are separate, spatially distinct perivascular niches for quiescent and proliferating HSCs in the BM. ${ }^{41}$

During development, perivascular hematopoietic niches have been also described to be present in other organs, like the placenta ${ }^{57}$ and spleen. ${ }^{25}$ Additionally, a recent report showed that HSCs expand around fetal liver portal vessels, suggesting that blood vessels provide an adaptive niche, serving hematopoiesis at multiple developmental stages of mammalian life. .58

\section{Heterogeneity of cells of the niche}

\section{Non-hematopoietic types}

Osteoblasts-Cells of the osteoblastic lineage have been proposed to function as critical modulators of HSCs in the BM. ${ }^{59}$ In vitro culture experiments have suggested that 
osteoblastic cell lines can expand the number of HSCs two- to fourfold. ${ }^{60}$ In addition, when co-transplanted with HSCs, osteoblasts can increase the engraftment rate. ${ }^{61}$ Osteoblasts produce a wide array of growth factors and cytokines, important for HSCs maturation. ${ }^{60,62}$ Osteopontin, an osteoblast-secreted protein, participates in HSC location and is a negative regulator of their proliferation. ${ }^{63,64}$ Furthermore, angiopoietin-1 expressed by osteoblasts has been suggested to regulate HSC numbers through the activation of Tie-2 signaling pathway, ${ }^{65}$ while Jagged 1, a Notch receptor ligand, supports an increase in HSC numbers. ${ }^{66}$ Mutant mice with conditional deletion of BMP receptor type IA or genetic alteration to produce osteolineage-specific activated PTH led to abnormal bone formation with increased osteoblast numbers that correlated with increased HSC numbers in the BM. ${ }^{66}$ Genetic depletion of osteolineage cells by the use of GCV in transgenic mice expressing herpesvirus thymidine kinase gene under the control of a constitutive 2.3-kb fragment of the rat $\mathrm{a}(1)$ type I collagen promoter leads to BM hypocellularity and extramedullary hematopoiesis within the spleen and liver. ${ }^{67}$ After GCV is withdrawn, osteoblasts reappear in the bone compartment, together with a decrease in extramedullary and a recovery of medullary hematopoiesis. ${ }^{67}$

Since constitutive promoter expression may not be specific to mature osteoblasts but could be expressed up to the MSC stage, ${ }^{68}$ specificities with careful lineage tracing to assess transgenic expression and recombination are needed to define osteolineage cells. Indeed, adipo-osteogenic progenitors ${ }^{69}$ and Nestin $^{+}$cells ${ }^{70}$ express the osteogenic proteins Runx 2 and Osterix. In keeping with this idea, osteoblastic expansion does not always promote HSC expansion in the BM. ${ }^{71}$ Strontium, which inhibits both osteoclast resorbing activity and osteoblast bone-forming activity, ${ }^{72}$ did not increase the number or frequency of HSCs when administered in doses higher than normally detected in the body. ${ }^{71}$ Osteocytes, derived from osteoblasts that became embedded within the bone matrix, appear to have an inhibitory effect on HSC support. ${ }^{73}$ More recent studies have shown that cells of the osteoblastic lineage may support lymphopoiesis. Elimination of osteoblasts in Col2.3-TK transgenic mice depleted pre-pro-B and pro-B cells from the $\mathrm{BM}^{74}$ without affecting the HSCs. ${ }^{75}$ Depleting CXCL12 from osteoblasts in Col2.3-cre mice leads to loss of lymphoid progenitors in the BM without affecting the number of HSCs. ${ }^{76}$ Thus, the exact function of osteoblasts in hematopoiesis remains unclear; most recent studies indicate that they are dispensable for HSC maintenance and more important to lymphoid progenitors.

Endothelial cells-The endothelium forms the inner cellular lining of blood vessels. ${ }^{77}$ Because most HSCs were found to be associated with blood vessels, endothelial cells were suggested to play important roles in HSC maintenance in sinusoids. ${ }^{78}$ An intact vasculature is necessary for HSC recovery and hematopoietic reconstitution following total body irradiation and BM transplantation. ${ }^{79-81}$ Several studies described the expansion of HSCs on an endothelial cell feeder system in vitro. ${ }^{82-86}$ In addition, BM endothelial cells have been proposed to produce soluble factors that have the ability to promote HSCs self-renewal and regeneration in vivo. ${ }^{80,81,87-90}$

HSCs are found in close contact with endothelial cells at all developmental stages. Endothelial cells harvested from embryonic tissues have been shown to support the expansion of adult HSC cells in vitro. ${ }^{91,92}$ On the contrary, endothelial cells isolated from 
adult non-hematopoietic organs do not display an HSC-supportive activity in vitro. ${ }^{93}$ These observations indicate tissue-specific functional characteristics of endothelial cells.

Deletion of glycoprotein 130 from endothelial and hematopoietic cells with Tie2-cre mice resulted in BM dysfunction and severe anemia by adulthood. Hematopoietic defects remained after transplantation of wild-type BM into irradiated glycoprotein 130-deficient mice, while normal hematopoiesis was reconstituted after transplantation of glycoprotein 130-deficient BM into irradiated wild-type mice, indicating that glycoprotein 130 expression on endothelial cells rather than hematopoietic cells influenced hematopoiesis. ${ }^{94}$ Deletion of $S c f$ in the same Tie2-cre mice led to reduced HSC frequencies with diminished repopulation capacities after BM transplantation, suggesting that SCF derived from endothelial cells contributes to HSC maintenance. ${ }^{95}$ Additionally, despite the fact that depletion of CXCL12 from endothelial cells using the same mouse model had no effect on the number of HSCs, it resulted in a slight decrease of long-term repopulating activity. ${ }^{96}$

Endothelial cells are heterogeneous in their morphology, gene expression, antigen composition, distribution, and function. Endothelial cell phenotypes vary between different tissues, as well as between different segments of the vasculature within the same tissue. ${ }^{97,98}$ It remains unknown, for instance, whether arteriolar and sinusoidal endothelial cells differ. Elucidating their molecular differences in the BM may reveal novel concepts about these cells' role in the HSC niche. ${ }^{98}$

Pericytes-Pericytes have long projections that encircle the blood vessel wall in almost all tissues. ${ }^{99-106}$ They are defined by their anatomical locations in combination with several molecular markers, such as platelet-derived growth factor receptor $\beta$ (PDGFR $\beta$ ), CD146, neuron-glial 2 (NG2), aSMA, desmin, and Nestin. However, marker expression is highly dependent on the tissue type, and could often be affected by the pathologic state of the organ. $^{99}$

Pericytes have been suggested to influence HSCs in both mice and humans. ${ }^{70,95,107}$ Using Nestin-GFP transgenic mice, Nestin ${ }^{+}$perivascular cells have been defined as central components of the HSC niche, regulating HSCs via the expression of C-X-C motif chemokine 12 (CXCL12) and stem cell factor (SCF) ${ }^{70,108}$. In vivo ablation of those cells in the BM significantly reduces the number of HSCs. ${ }^{70}$ Cells located in a pericytic position close to the vasculature enriched in CXCL12 have been described and named CXCL-12 abundant reticular (CAR) cells. ${ }^{50}$ The transcription factor forkhead box C1 (FoxC1) in CAR cells has recently been identified as essential for maintenance of HSCs in vivo. ${ }^{109}$ Selective ablation of CAR cells in the BM leads to reduction of HSCs. ${ }^{69}$ Additionally, $\mathrm{PDGFRa}^{+} \mathrm{Sca}^{-1}{ }^{+}(\mathrm{PaS})$ cells, ${ }^{110}$ located in the arterial perivascular space, ${ }^{111}$ and leptin receptor-expressing pericytes have been suggested to regulate HSC maintenance in the BM. ${ }^{95,96}$ These cells exhibit common characteristics in that leptin receptor ${ }^{+}$stromal cells overlap with CAR cells ${ }^{76}$ and represent a large subset (nearly $90 \%$ ) of Nestin-GFP ${ }^{+}$cells in the BM. Nestin-GFP ${ }^{+}$cells also overlap with PaS cells, although most PaS cells are associated with the bone itself (most marrow Nestin-GFP ${ }^{+}$cells do not express Sca-1). ${ }^{108}$ 
There are at least two varieties of BM pericytes according to their location in the blood vessels: arteriolar and sinusoidal. ${ }^{41}$ Sinusoids are structurally different from arterioles in that they are lined by a single layer of endothelium, while arterioles are thicker-walled blood vessels. ${ }^{112}$ Arteriolar and sinusoidal pericytes can be separated in Nestin-GFP transgenic mice according to Nestin-GFP transgene expression level. ${ }^{41}$ Sinusoidal pericytes are more numerous and reticular in shape. They express lower levels of the Nestin-GFP transgene, whereas rare arteriolar Nestin-GFP bright pericytes exhibit a classic pericyte morphology. Additionally, arteriolar pericytes express the pericytic marker NG2 proteoglycan, but do not express leptin receptor; while sinusoidal pericytes express leptin receptor, but lack NG2 expression. ${ }^{41}$ The embryonic origin and the developmental relationships of BM pericyte subpopulations have yet to be elucidated. Interestingly, an evaluation of the cell cycle status demonstrated that arteriolar pericytes are largely quiescent. ${ }^{41}$ Tridimensional imaging of the adult mouse BM has revealed that the majority of dormant HSCs are situated close to arterioles; and genetic depletion of arteriolar pericytes resulted in migration of HSCs away from the arterioles, switching them into non-quiescent status. ${ }^{41}$ This suggests that arteriolar pericytes promote HSC dormancy, essential for HSC maintenance in the BM. ${ }^{41}$ Nevertheless, the molecular mechanisms by which arteriolar pericytes regulate HSC quiescence remain to be clearly defined.

Adipocytes-It has been suggested that BM fat is unlike white and brown fat of other tissues. ${ }^{113-115}$ Adipocytes appear dispersed within the BM, instead of being grouped into lobules, and are smaller than visceral and subcutaneous adipocytes. ${ }^{116,117}$ Although older studies suggested that adipocytes were passive occupants of the BM, ${ }^{118}$ simply filling the spaces after trabecular bone loss, a regulatory role in the BM has emerged with recent studies. ${ }^{113,118,119}$ A specific marker for BM adipocytes has not yet been determined, but there are several differentially expressed genes in BM adipocytes compared to subcutaneous and epididymal adipocytes. ${ }^{120,121}$ A reduction of adipocyte numbers with increased size has been noted with disease and aging in the BM. ${ }^{113,119,122-125}$ This also has been associated with a decrease in cellularity ${ }^{126}$ and induction of myeloid-biased differentiation in HSCs. ${ }^{1}$ Nevertheless, no direct link between an increase in adipose tissue and HSC myeloid bias during aging has been established.

Similar to adipocytes from other tissues, BM adipocytes are able to secrete cytokines, fatty acids, and hormones, and have a potential to influence the function of other neighboring cells in the BM microenvironment via paracrine mechanisms. ${ }^{119,124,127-130}$ The details of those mechanisms are still being unraveled. For instance, in vitro, BM adipocytes secrete more leptin than subcutaneous adipocytes. ${ }^{131}$ Some investigators have suggested that this is attributable to an important role of leptin in myelopoiesis, ${ }^{132}$ where, in the diet-induced obesity mouse model, hematopoiesis is enhanced due the high leptin levels in the BM. ${ }^{130}$ However, in vitro studies differ on their conclusions about the effect of adipocytes on HSCs. While some studies show that adipocyte negative regulation can balance the positive effects of other cellular components of the BM niche on $\mathrm{HSCs},{ }^{133}$ others suggest that adipocytes can support HSC growth and differentiation in vitro. ${ }^{134,135}$ However, alterations of adipocyte number and volume in vivo have been reported to have no effect on HSCs. ${ }^{134,135}$ 
A great number of studies indicate that adipocytes inhibit HSCs function as well as hematopoietic reconstitution. ${ }^{136-138}$ Lipid-filled BM adipocytes have been connected to the repression of growth and differentiation of HSCs ${ }^{136,139}$ and considered negative regulators of the hematopoietic niche. ${ }^{69,140}$ Hematopoietic recovery is improved following chemotherapy in mice with chemically inhibited adipogenesis. ${ }^{141}$ In mouse tail vertebrae, where BM cavities are densely filled with adipocytes, the few HSCs detected are largely quiescent. ${ }^{136}$ The adipocyte suppressive function has been attributed to the reduced production of granulocyte colony-stimulating factors (GM-CSF and G-CSF) and to the increased secretion of lipocalin-2 and neuropilin. ${ }^{136,142,143}$ Interestingly, at the same time that adipocytes prevent HSC expansion, they seem to positively affect HSCs via secretion of adiponectin and $\mathrm{TNFa},{ }^{144,145}$ playing a role in preserving the hematopoietic stem cell pool. ${ }^{136}$ Whether the role of BM adipocytes in the HSC niche differs under various physiological conditions, including aging or obesity, remains unclear.

Schwann cells-Schwann cells are the principal glial cells of the peripheral nervous system. In the BM, they are present in their unmyelinated form associated with sympathetic and sensory nerve fibers. ${ }^{70,146,147}$ Until recently, unmyelinated Schwann cells received relatively little scientific attention, with only a poor understanding having developed of their function outside the nervous system. Schwann cells maintain the ability to revert to an immature phenotype in response to injury and disease and, by doing so, they can then reenter the cell cycle, proliferate, and affect the microenvironment in which they are located. ${ }^{148,149}$ Schwann cells were shown to produce several cytokines, ${ }^{150}$ and to express cytokine receptors as well. ${ }^{151}$

Recent studies have suggested that BM Schwann cells regulate the hibernation and activation of HSCs. ${ }^{152}$ In that study, using immunohistochemistry, the expression of active TGF $\beta$ was proposed to be restricted to BM Schwann cells. ${ }^{152}$ BM denervation reduced the number of cells producing active TGF $\beta$, leading to a loss of HSCs from the BM. ${ }^{152}$ However, denervation not only affects Schwann cells; for instance, $\beta$-adrenergic signals from the sympathetic nervous system have been shown to regulate enforced ${ }^{49}$ and circadian HSC egress. ${ }^{153}$ Moreover, in addition to Schwann cells, other cells, including megakaryocytes, produce TGF $\beta$ in the BM. ${ }^{154}$ TGF $\beta 1$ derived from megakaryocytes has been shown to maintain HSC quiescence. ${ }^{56}$ Most of BM innervation-and Schwann cell ensheathing of those nerve fibers - runs along arterioles in the BM. ${ }^{155}$ As arterioles contain multiple cell types, the identity of the cell promoting HSC quiescence remains unknown. Interestingly, both pericytes and Schwann cells express NG2 proteoglycan and may contribute to the arteriolar HSC niche. ${ }^{41,156}$ It will be interesting to ascertain whether BM Schwann cells differ from Schwann cells from other tissues. Successful isolation of BM Schwann cells may enable the discovery of novel niche factors possibly expressed by those cells.

Nerves-Signals from the sympathetic nervous system have been identified as regulatory components of the HSC niche. ${ }^{13,157,158}$ Sympathetic nerves produce catecholamines, which are delivered to the BM microenvironment by the blood circulation or by secretion from the nerve endings acting in paracrine signaling. ${ }^{159}$ Sympathectomy achieved by treating mice with the neurotoxin 6-hydroxydopamine does not affect HSCs number, ${ }^{49,153,160,161}$ but it 
impairs mobilization in response to G-CSF. ${ }^{49}$ Under steady-state conditions, HSCs egress from the BM to enter the blood circulation predominantly in the morning in rodents (night in humans), ${ }^{153}$ and migrate to the tissues during the night in rodents (day in humans). ${ }^{162-165}$ Adrenergic signaling reduces CXCL12 expression in the BM. ${ }^{153,166}$ Moreover, recent evidence shows that chemotherapy-induced injury of sympathetic nerves in the BM prevents hematopoietic recovery, suggesting that treatment with neuroprotective drugs during chemotherapy would preserve HSC function in the BM niche. ${ }^{161}$ Induction of sympathetic neuropathy by malignant cells has recently been demonstrated. ${ }^{167,168}$

HSCs express catecholaminergic receptors, suggesting that they are able to directly respond to signals from the sympathetic nervous system. ${ }^{169}$ Treatment of HSCs with dopamine agonists enhances colony formation in vitro, albeit only in the presence of G-CSF. ${ }^{169}$ Pretreatment of HSCs with dopamine agonists enhances their ability to engraft. ${ }^{169}$ Additionally, norepinephrine treatment of HSCs also enhances both colony-formation capabilities in vitro and engraftment in vivo. ${ }^{159,169}$ Additionally, the sympathetic nervous system adjacent to the dorsal aorta plays an important role in HSC specification during development. ${ }^{170}$ Overall, these studies suggest a contribution of the sympathetic nervous system in regulating the HSC niche.

\section{Hematopoietic types}

Macrophages-Macrophages play diverse roles in the bone and marrow. At the sites of bone remodeling, they are anatomically juxtaposed with endosteal osteoblasts and participate in bone mineralization. ${ }^{171-173}$ Radio-resistant macrophages protect the HSC pool from exhaustion by producing prostaglandin E2 after irradiation. ${ }^{174} \mathrm{BM}$ resident macrophages are defined based on differential expression of several molecular markers, such as Gr-1, F4/80, CD115, and CD169. ${ }^{175}$ Their numbers are reduced during G-CSF-induced HSC mobilization, and, following their loss, HSCs egress to the peripheral circulation. ${ }^{174176}$

Macrophages promote HSC retention in the BM by regulating the expression of CXCL12 by Nestin- $\mathrm{GFP}^{+} \mathrm{MSC}$ via a soluble factor secreted by $\mathrm{CD} 169^{+}$macrophages ${ }^{54}$ Recent studies have suggested that this factor was oncostatin M. ${ }^{177}$ Thus, macrophages and sympathetic nerves exert the opposite action to the niche, forming a regulatory loop. ${ }^{54} \mathrm{HSC}$ retention in the BM and the spleen relies at least partially on a ligand for VCAM-1, integrin VLA-4, ${ }^{178-180}$ which is expressed by macrophages. A recent study described that macrophages are important players in splenic HSC retention, as depleting macrophages using inducible diphtheria toxin receptor expression at the $C D 169$ locus mice or silencing VCAM-1 in macrophages caused release of HSCs from the spleen. ${ }^{181}$ Additionally, a separate subpopulation of macrophages expressing high levels of a-smooth muscle actin and cyclooxygenase 2 was recently identified. This rare macrophage population synthesizes prostaglandin E2, which increases CXCL12 expression in Nestin-GFP ${ }^{+} \mathrm{MSCs}^{182}$ and CXCR4 expression on HSCs, ${ }^{183}$ thus improving the survival and maintenance of HSCs in the BM. Moreover, macrophages have been suggested to regulate HSC egress from the BM after phagocytosis of aged neutrophils. ${ }^{184}$

Interestingly, macrophages are also key mediators of the neuroprotective effect of neuropeptide Y, and thus contribute to HSC survival in the BM. Neuropeptide Y regulates 
homeostasis in several tissues through Y receptors. ${ }^{185-187}$ A recent study shows that neuropeptide $\mathrm{Y}$ deficiency impairs HSC survival and BM regeneration. Furthermore, pharmacological elevation of neuropeptide $\mathrm{Y}$ prevented the deficits, while neuropeptide $\mathrm{Y}$ injection into mice lacking the $\mathrm{Y} 1$ receptor specifically in macrophages did not rescue BM dysfunction. ${ }^{188}$

Macrophages are also involved in both steady-state and stress-induced erythropoiesis. In vivo macrophage depletion leads to a decreased number of erythroblasts in the BM and induces anemia with characteristics of iron-deficiency anemia, which is not corrected by iron supplementation. Macrophage depletion also delays erythropoietic recovery following acute blood loss, myeloablation, or challenge with hemoglobin-oxidizing phenylhydrazine (PHZ) ${ }^{53,54}$ Interestingly, polycythemia vera, which is characterized by elevated erythropoiesis, can be improved via macrophage ablation. Macrophage depletion reduces hematocrit and red blood cell counts in a mouse model of polycythemia vera driven by the JAK2 ${ }^{\mathrm{V} 617 \mathrm{~F}}$ mutation. ${ }^{54}$ These studies suggest that macrophages are critical components of erythroid maturation in the steady state, as well as during erythropoietic rescue after stress and disease. It remains unknown how erythroblastic island macrophages differ functionally from other BM resident macrophages. Erythroblastic island macrophages thought to be very large (with diameter exceeding $15 \mu \mathrm{m}$ ) express F4/80 and do not express Mac1; ${ }^{189}$ however, a unique molecular marker for erythroblastic island macrophages remains to be discovered. Overall, these findings suggest that macrophages are key components of the BM niche promoting the maintenance and retention of HSCs.

Osteoclasts-Osteoclasts originate from hematopoietic progenitors via mononuclear phagocytes. ${ }^{190}$ They are the only cell type capable of bone resorption in the human body, allowing the renewal of the skeleton but also opening space in the BM for hematopoietic cells. Osteoclasts have been suggested to contribute to HSC release via enzyme secretion, enhancing mobilization. ${ }^{191}$ On the other hand, it has been hypothesized that osteoclastic bone resorption releases calcium, increasing its concentration at the endosteal region, which attracts and retains HSCs that express calcium-sensing receptors in the BM. ${ }^{39}$ Bone resorption also produces active TGF $\beta$, which can act on HSCs. ${ }^{192}$ Osteoclast inhibition by bisphosphonates causes a reduction in the number of HSCs and delays hematopoietic recovery. ${ }^{193}$ Using a mouse model with loss of osteoclast activity, osteoclasts have been shown to regulate mesenchymal cell differentiation and HSC maintenance. ${ }^{194}$

Megakaryocytes-A subset of HSCs is located in close proximity to megakaryocytes in the BM. ${ }^{55,195,196}$ Several mouse models with increased number of megakaryocytes have also demonstrated increased bone mass. ${ }^{197}$ Thus, some studies have suggested a complex interaction between megakaryocytes, HSCs, and the osteolineage within the BM.

Accordingly, after BM radioablation, host megakaryocytes are recruited to the endosteum, where osteoblasts undergo rapid expansion in response to the secretion of megakaryocytederived mesenchymal growth factors, such as platelet-derived growth factor- $\beta$ (PDGF- $\beta$ ), to promote HSC engraftment and hematopoietic reconstitution after BM transplantation. ${ }^{198}$ The migration of megakaryocytes to the endosteum is thought to depend on thrombopoietin 
signaling, since the inhibition of c-Mpl reduces megakaryocyte migration after radioablative conditioning. 198

More recent findings have identified a direct HSC regulation by megakaryocytes in steadystate hematopoiesis. 55,56,195 Ablation of megakaryocytes reduces HSC engraftment and proliferation. ${ }^{195,198}$ Thrombopoietin administration to megakaryocyte-depleted mice restores the number of quiescent $\mathrm{HSCs},{ }^{195}$ suggesting that thrombopoietin may contribute to regulation of HSCs by megakaryocytes. Megakaryocytes produce high levels of TGF $\beta$, which regulate HSCs. ${ }^{199}$ Conditional deletion of $T g f b 1$ in megakaryocytes increases HSC activation and proliferation in young mice. ${ }^{56}$ In addition, TGF $\beta$ injection into megakaryocyte-depleted mice restores HSC quiescence. ${ }^{56}$ Under homeostatic conditions, megakaryocytes maintain HSC quiescence through TGF $\beta$ signaling; while under stress megakaryocytes promote $\mathrm{HSC}$ expansion via $\mathrm{FGF}-1$ production. ${ }^{56} \mathrm{CXCL} 4$, which is produced by megakaryocytes, negatively regulates HSC proliferation, reduces HSC numbers, and decreases engraftment. ${ }^{55}$ An increase in HSC number, proliferation, and repopulating activity was observed in $C X C L 4$ knockout mice. ${ }^{55}$ As megakaryocytes produce multiple cytokines (e.g., thrombopoietin, TGF $\beta$, and CXCL4), it is possible that their effect on HSCs results from the balance of all those and probably more molecules. Interestingly, megakaryocytes physically associate with approximately $20 \%$ of HSCs in the BM. ${ }^{55}$ It remains to be studied whether the function of those HSCs differs from that of the rest of the HSCs in the BM. Overall, these observations confirm that megakaryocytes serve as HSCderived niche cells directly regulating HSC function.

Lymphocytes-Lymphocytes, essential for both cell-mediated and antibody-mediated immunity, are widely distributed throughout the BM parenchyma and make up a major fraction of total BM mononuclear cells. ${ }^{200}$ Lymphocytes have been suggested to influence hematopoiesis, potentially through direct cellular interactions with the HSCs. ${ }^{201}$ Natural killer cells have been suggested to play a negative role in HSC differentiation. ${ }^{202}$ Experiments in adult mice harboring a null mutation in the common $\gamma$ chain indicated that cytokines secreted by activated T cells in the BM modulate normal hematopoiesis. ${ }^{203}$ Even though, in the absence of activated $\mathrm{BM}, \mathrm{CD} 4^{+} \mathrm{T}$ cell $\mathrm{HSC}$ can give rise to committed myeloid progenitors, these progenitors exhibit impaired ability to complete their differentiation program and give rise to mature cells. ${ }^{204}$ After adoptive transfer of CD4 ${ }^{+} \mathrm{T}$ cells, this defective myeloid differentiation is restored in T cell-deficient mice, suggesting that $\mathrm{CD}^{+} \mathrm{T}$ cells are essential to the maintenance of basal hematopoiesis in the BM. ${ }^{204}$

Regulatory T cells make up one third of all CD4+ ${ }^{+}$cells in the BM. ${ }^{205,206}$ Depletion experiments and co-transfer of BM with regulatory $\mathrm{T}$ cells indicated that these cells suppress colony formation and myeloid differentiation of HSCs. ${ }^{207}$ Moreover, FoxP3 ${ }^{+}$regulatory T cells colocalize with HSCs in the endosteal surface in the calvarial and trabecular BM, and this colocalization is lost after depletion of regulatory T cells. ${ }^{208}$ However, whether this interaction is biologically relevant to the homeostatic HSC maintenance is still unclear. Furthermore, regulatory $\mathrm{T}$ cells have been suggested to provide an immune-privileged niche in the BM, protecting HSCs from immune attacks. ${ }^{208}$ 
Neutrophils-Neutrophils are the most abundant subpopulation of leukocytes, with a $\mathrm{BM}$ reserve estimated to be $6 \times 10^{11}$ in humans and $12 \times 10^{7}$ in mice. ${ }^{209,210}$ Neutrophils have short circulating half-life (6-8 h), after which they quickly migrate to tissues where they perform their functions. ${ }^{209}$ Serine proteases derived from neutrophils are capable of cleaving several cytokines and receptors essential for HSC retention in vitro, including CXCL12, ${ }^{211} \mathrm{CXCR} 4,{ }^{212} \mathrm{VCAM}-1,{ }^{213} \mathrm{c}-\mathrm{Kit},{ }^{214}$ and SCF,${ }^{215}$ suggesting that activated neutrophils create a proteolytic microenvironment that may contribute to HSC release from the BM. However, it was shown that, in mice lacking these proteases, G-CSF-induced HSC mobilization proceeds normally, ${ }^{216}$ suggesting that serine proteases are not essential for BM egress.

G-CSF induces neutrophil expansion in the BM, which may lead to MSC and osteoblast apoptosis and reductions in the expression of factors that are responsible for HSC retention in the BM. ${ }^{217}$ However, neutrophil number in the BM does not necessarily correlate with HSC mobilization. ${ }^{176}$ Another study showed that depleting circulating neutrophils increased CXCL12-expressing stromal cells number and CXCL12 protein levels, which resulted in enhanced retention of HSCs in the BM. ${ }^{184}$ Those effects are lost in mice in which neutrophils do not express CXCR4 and lack tropism to the BM, indicating that these effects may be exerted locally in the BM. ${ }^{184,218}$ Ablation of BM macrophages reverses the nichemodulating functions of neutrophils, indicating that the effect of neutrophils on the hematopoietic niche is dependent on macrophages. Together, these data explains how the daily clearance of aged neutrophils in the BM generates signals that affect HSCs in the BM niches. ${ }^{184}$

\section{Conclusions and perspectives}

The studies discussed in this review illustrate the contributions of multiple cell populations within the BM microenvironment to the complex regulation of HSC function. The use of sophisticated genetic tools has demonstrated that changes to the niche composition can have profound effects on HSC behavior. Recombination-based technology provides powerful means to interrogate the cellular and molecular components of niches. However, it is completely dependent on the promoter specificity and activity driving Cre, which must be characterized extensively before reaching conclusions about cell specificity or origins. Future clarification of the interactions between HSCs and their microenvironments during embryonic development may lead to improved methods to exploit the clinical potential of HSCs. Procedures to induce HSC self-renewal will benefit from this knowledge. Our increased understanding of healthy HSC niches should foster studies on the altered HSC niches in BM disorders. Targeting the niche itself is an attractive potential possibility for the treatment of hematologic disorders. The balance of extrinsic influences from the supportive niche may also vary under different physiological conditions. Newborn, adult, and aged HSCs have different physiological demands. The exploration of how the BM microenvironment ages will reveal essential information for the treatment of age-related BM illnesses. Likewise, understanding how the niche controls HSC function during stress situations, such as infections, radiotherapy, and chemotherapy, is needed. Recent studies suggest that BM endothelial cells play crucial roles in HSC recovery following radiation injury. ${ }^{89,219} \mathrm{~A}$ big challenge for the future will be to translate animal research into humans. 
Improving the availability of human tissue samples will be essential to reach this goal.

Enormous advancement has been accomplished in our understanding of the importance and the complexity of the BM microenvironment to HSC function and to the health of the organism as a whole. The best is yet to come.

\section{References}

1. Pang WW, et al. Human bone marrow hematopoietic stem cells are increased in frequency and myeloid-biased with age. Proceedings of the National Academy of Sciences of the United States of America. 2011; 108:20012-20017. [PubMed: 22123971]

2. Oguro H, Ding L, Morrison SJ. SLAM family markers resolve functionally distinct subpopulations of hematopoietic stem cells and multipotent progenitors. Cell stem cell. 2013; 13:102-116. [PubMed: 23827712]

3. Gazit R, Weissman IL, Rossi DJ. Hematopoietic stem cells and the aging hematopoietic system. Seminars in hematology. 2008; 45:218-224. [PubMed: 18809091]

4. Seita J, Weissman IL. Hematopoietic stem cell: self-renewal versus differentiation. Wiley interdisciplinary reviews. Systems biology and medicine. 2010; 2:640-653. [PubMed: 20890962]

5. Zon LI. Intrinsic and extrinsic control of haematopoietic stem-cell self-renewal. Nature. 2008; 453:306-313. [PubMed: 18480811]

6. Laurenti E, Dick JE. Molecular and functional characterization of early human hematopoiesis. Annals of the New York Academy of Sciences. 2012; 1266:68-71. [PubMed: 22901258]

7. Benveniste $P$, et al. Hematopoietic stem cells engraft in mice with absolute efficiency. Nature immunology. 2003; 4:708-713. [PubMed: 12766767]

8. Frelin C, et al. GATA-3 regulates the self-renewal of long-term hematopoietic stem cells. Nature immunology. 2013; 14:1037-1044. [PubMed: 23974957]

9. Till JE, Mc CE. A direct measurement of the radiation sensitivity of normal mouse bone marrow cells. Radiation research. 1961; 14:213-222. [PubMed: 13776896]

10. Mirantes C, Passegue E, Pietras EM. Pro-inflammatory cytokines: emerging players regulating HSC function in normal and diseased hematopoiesis. Experimental cell research. 2014; 329:248254. [PubMed: 25149680]

11. Thomas ED, et al. Intravenous infusion of bone marrow in patients receiving radiation and chemotherapy. The New England journal of medicine. 1957; 257:491-496. [PubMed: 13464965]

12. Morrison SJ, Scadden DT. The bone marrow niche for haematopoietic stem cells. Nature. 2014; 505:327-334. [PubMed: 24429631]

13. Mendelson A, Frenette PS. Hematopoietic stem cell niche maintenance during homeostasis and regeneration. Nature medicine. 2014; 20:833-846.

14. Schofield R. The relationship between the spleen colony-forming cell and the haemopoietic stem cell. Blood cells. 1978; 4:7-25. [PubMed: 747780]

15. Rashidi NM, et al. In vivo time-lapse imaging shows diverse niche engagement by quiescent and naturally activated hematopoietic stem cells. Blood. 2014; 124:79-83. [PubMed: 24850759]

16. Orkin SH, Zon LI. Hematopoiesis: an evolving paradigm for stem cell biology. Cell. 2008; 132:631-644. [PubMed: 18295580]

17. Guenechea G, et al. Distinct classes of human stem cells that differ in proliferative and self-renewal potential. Nature immunology. 2001; 2:75-82. [PubMed: 11135582]

18. Ema H, et al. Quantification of self-renewal capacity in single hematopoietic stem cells from normal and Lnk-deficient mice. Developmental cell. 2005; 8:907-914. [PubMed: 15935779]

19. Osawa M, et al. Long-term lymphohematopoietic reconstitution by a single CD34-low/negative hematopoietic stem cell. Science. 1996; 273:242-245. [PubMed: 8662508]

20. Morrison SJ, et al. Identification of a lineage of multipotent hematopoietic progenitors. Development. 1997; 124:1929-1939. [PubMed: 9169840] 
21. Yang L, et al. Identification of Lin(-)Sca1(+)kit(+)CD34(+)Flt3- short-term hematopoietic stem cells capable of rapidly reconstituting and rescuing myeloablated transplant recipients. Blood. 2005; 105:2717-2723. [PubMed: 15572596]

22. Muller-Sieburg CE, et al. Stem cell heterogeneity: implications for aging and regenerative medicine. Blood. 2012; 119:3900-3907. [PubMed: 22408258]

23. Yamamoto R, et al. Clonal analysis unveils self-renewing lineage-restricted progenitors generated directly from hematopoietic stem cells. Cell. 2013; 154:1112-1126. [PubMed: 23993099]

24. Purton LE, Scadden DT. Limiting factors in murine hematopoietic stem cell assays. Cell stem cell. 2007; 1:263-270. [PubMed: 18371361]

25. Kiel MJ, et al. SLAM family receptors distinguish hematopoietic stem and progenitor cells and reveal endothelial niches for stem cells. Cell. 2005; 121:1109-1121. [PubMed: 15989959]

26. Kent DG, et al. Prospective isolation and molecular characterization of hematopoietic stem cells with durable self-renewal potential. Blood. 2009; 113:6342-6350. [PubMed: 19377048]

27. Benveniste $\mathrm{P}$, et al. Intermediate-term hematopoietic stem cells with extended but time-limited reconstitution potential. Cell stem cell. 2010; 6:48-58. [PubMed: 20074534]

28. Gekas C, Graf T. CD41 expression marks myeloid-biased adult hematopoietic stem cells and increases with age. Blood. 2013; 121:4463-4472. [PubMed: 23564910]

29. Muller-Sieburg CE, et al. Myeloid-biased hematopoietic stem cells have extensive self-renewal capacity but generate diminished lymphoid progeny with impaired IL-7 responsiveness. Blood. 2004; 103:4111-4118. [PubMed: 14976059]

30. Dykstra B, et al. Long-term propagation of distinct hematopoietic differentiation programs in vivo. Cell stem cell. 2007; 1:218-229. [PubMed: 18371352]

31. Benz C, et al. Hematopoietic stem cell subtypes expand differentially during development and display distinct lymphopoietic programs. Cell stem cell. 2012; 10:273-283. [PubMed: 22385655]

32. Challen GA, et al. Distinct hematopoietic stem cell subtypes are differentially regulated by TGFbeta1. Cell stem cell. 2010; 6:265-278. [PubMed: 20207229]

33. Sanjuan-Pla A, et al. Platelet-biased stem cells reside at the apex of the haematopoietic stem-cell hierarchy. Nature. 2013; 502:232-236. [PubMed: 23934107]

34. Copley MR, Beer PA, Eaves CJ. Hematopoietic stem cell heterogeneity takes center stage. Cell stem cell. 2012; 10:690-697. [PubMed: 22704509]

35. Eaves CJ. Hematopoietic stem cells: concepts, definitions, and the new reality. Blood. 2015; 125:2605-2613. [PubMed: 25762175]

36. Ema H, Morita Y, Suda T. Heterogeneity and hierarchy of hematopoietic stem cells. Experimental hematology. 2014; 42:74-82 e72. [PubMed: 24269919]

37. Ellis SL, et al. The relationship between bone, hemopoietic stem cells, and vasculature. Blood. 2011; 118:1516-1524. [PubMed: 21673348]

38. Nombela-Arrieta C, et al. Quantitative imaging of haematopoietic stem and progenitor cell localization and hypoxic status in the bone marrow microenvironment. Nature cell biology. 2013; 15:533-543. [PubMed: 23624405]

39. Adams GB, et al. Stem cell engraftment at the endosteal niche is specified by the calcium-sensing receptor. Nature. 2006; 439:599-603. [PubMed: 16382241]

40. Guezguez B, et al. Regional localization within the bone marrow influences the functional capacity of human HSCs. Cell stem cell. 2013; 13:175-189. [PubMed: 23910084]

41. Kunisaki Y, et al. Arteriolar niches maintain haematopoietic stem cell quiescence. Nature. 2013; 502:637-643. [PubMed: 24107994]

42. Haylock DN, et al. Hemopoietic stem cells with higher hemopoietic potential reside at the bone marrow endosteum. Stem cells. 2007; 25:1062-1069. [PubMed: 17420230]

43. Acar M, et al. Deep imaging of bone marrow shows non-dividing stem cells are mainly perisinusoidal. Nature. 2015; 526:126-130. [PubMed: 26416744]

44. Kohler A, et al. Altered cellular dynamics and endosteal location of aged early hematopoietic progenitor cells revealed by time-lapse intravital imaging in long bones. Blood. 2009; 114:290298. [PubMed: 19357397] 
45. De Bruyn PP, Breen PC, Thomas TB. The microcirculation of the bone marrow. The Anatomical record. 1970; 168:55-68. [PubMed: 4918907]

46. Munka V, Gregor A. Lymphatics and bone marrow. Folia morphologica. 1965; 13:404-412. [PubMed: 5842805]

47. Nees S, et al. Wall structures of myocardial precapillary arterioles and postcapillary venules reexamined and reconstructed in vitro for studies on barrier functions. American journal of physiology. Heart and circulatory physiology. 2012; 302:H51-68. [PubMed: 21984546]

48. Walmsley JG, et al. Quantitative morphology of arterioles from the hamster cheek pouch related to mechanical analysis. Microvascular research. 1982; 24:249-271. [PubMed: 7154983]

49. Katayama Y, et al. Signals from the sympathetic nervous system regulate hematopoietic stem cell egress from bone marrow. Cell. 2006; 124:407-421. [PubMed: 16439213]

50. Sugiyama T, et al. Maintenance of the hematopoietic stem cell pool by CXCL12-CXCR4 chemokine signaling in bone marrow stromal cell niches. Immunity. 2006; 25:977-988. [PubMed: 17174120]

51. Weiss L, Geduldig U. Barrier cells: stromal regulation of hematopoiesis and blood cell release in normal and stressed murine bone marrow. Blood. 1991; 78:975-990. [PubMed: 1868254]

52. Socolovsky M. Exploring the erythroblastic island. Nature medicine. 2013; 19:399-401.

53. Ramos P, et al. Macrophages support pathological erythropoiesis in polycythemia vera and betathalassemia. Nature medicine. 2013; 19:437-445.

54. Chow A, et al. CD169(+) macrophages provide a niche promoting erythropoiesis under homeostasis and stress. Nature medicine. 2013; 19:429-436.

55. Bruns I, et al. Megakaryocytes regulate hematopoietic stem cell quiescence through CXCL4 secretion. Nature medicine. 2014; 20:1315-1320.

56. Zhao M, et al. Megakaryocytes maintain homeostatic quiescence and promote post-injury regeneration of hematopoietic stem cells. Nature medicine. 2014; 20:1321-1326.

57. Rhodes KE, et al. The emergence of hematopoietic stem cells is initiated in the placental vasculature in the absence of circulation. Cell stem cell. 2008; 2:252-263. [PubMed: 18371450]

58. Khan JA, et al. Fetal liver hematopoietic stem cell niches associate with portal vessels. Science. 2015; 351:176-180. [PubMed: 26634440]

59. Taichman RS, Emerson SG. The role of osteoblasts in the hematopoietic microenvironment. Stem cells. 1998; 16:7-15. [PubMed: 9474743]

60. Taichman RS, Reilly MJ, Emerson SG. The Hematopoietic Microenvironment: Osteoblasts and The Hematopoietic Microenvironment. Hematology. 2000; 4:421-426. [PubMed: 11399584]

61. El-Badri NS, et al. Osteoblasts promote engraftment of allogeneic hematopoietic stem cells. Experimental hematology. 1998; 26:110-116. [PubMed: 9472800]

62. Taichman RS, Emerson SG. Human osteoblasts support hematopoiesis through the production of granulocyte colony-stimulating factor. The Journal of experimental medicine. 1994; 179:16771682. [PubMed: 7513014]

63. Nilsson SK, et al. Osteopontin, a key component of the hematopoietic stem cell niche and regulator of primitive hematopoietic progenitor cells. Blood. 2005; 106:1232-1239. [PubMed: 15845900]

64. Stier S, et al. Osteopontin is a hematopoietic stem cell niche component that negatively regulates stem cell pool size. The Journal of experimental medicine. 2005; 201:1781-1791. [PubMed: 15928197]

65. Arai F, et al. Tie2/angiopoietin-1 signaling regulates hematopoietic stem cell quiescence in the bone marrow niche. Cell. 2004; 118:149-161. [PubMed: 15260986]

66. Calvi LM, et al. Osteoblastic cells regulate the haematopoietic stem cell niche. Nature. 2003; 425:841-846. [PubMed: 14574413]

67. Visnjic D, et al. Hematopoiesis is severely altered in mice with an induced osteoblast deficiency. Blood. 2004; 103:3258-3264. [PubMed: 14726388]

68. Mizoguchi T, et al. Osterix marks distinct waves of primitive and definitive stromal progenitors during bone marrow development. Developmental cell. 2014; 29:340-349. [PubMed: 24823377]

69. Omatsu Y, et al. The essential functions of adipo-osteogenic progenitors as the hematopoietic stem and progenitor cell niche. Immunity. 2010; 33:387-399. [PubMed: 20850355] 
70. Mendez-Ferrer S, et al. Mesenchymal and haematopoietic stem cells form a unique bone marrow niche. Nature. 2010; 466:829-834. [PubMed: 20703299]

71. Lymperi $\mathrm{S}$, et al. Strontium can increase some osteoblasts without increasing hematopoietic stem cells. Blood. 2008; 111:1173-1181. [PubMed: 17971481]

72. Marie PJ. Strontium as therapy for osteoporosis. Current opinion in pharmacology. 2005; 5:633636. [PubMed: 16183330]

73. Calvi LM, et al. Osteoblastic expansion induced by parathyroid hormone receptor signaling in murine osteocytes is not sufficient to increase hematopoietic stem cells. Blood. 2012; 119:24892499. [PubMed: 22262765]

74. Zhu J, et al. Osteoblasts support B-lymphocyte commitment and differentiation from hematopoietic stem cells. Blood. 2007; 109:3706-3712. [PubMed: 17227831]

75. Bowers M, et al. Osteoblast ablation reduces normal long-term hematopoietic stem cell selfrenewal but accelerates leukemia development. Blood. 2015; 125:2678-2688. [PubMed: 25742698]

76. Ding L, Morrison SJ. Haematopoietic stem cells and early lymphoid progenitors occupy distinct bone marrow niches. Nature. 2013; 495:231-235. [PubMed: 23434755]

77. Ribatti D, et al. Endothelial cell heterogeneity and organ specificity. Journal of hematotherapy \& stem cell research. 2002; 11:81-90. [PubMed: 11847005]

78. Kiel MJ, et al. SLAM family receptors distinguish hematopoietic stem and progenitor cells and reveal endothelial niches for stem cells. Cell. 2005; 121:1109-1121. [PubMed: 15989959]

79. Hooper AT, et al. Engraftment and reconstitution of hematopoiesis is dependent on VEGFR2mediated regeneration of sinusoidal endothelial cells. Cell stem cell. 2009; 4:263-274. [PubMed: 19265665]

80. Kobayashi $\mathrm{H}$, et al. Angiocrine factors from Akt-activated endothelial cells balance self-renewal and differentiation of haematopoietic stem cells. Nature cell biology. 2010; 12:1046-1056. [PubMed: 20972423]

81. Salter AB, et al. Endothelial progenitor cell infusion induces hematopoietic stem cell reconstitution in vivo. Blood. 2009; 113:2104-2107. [PubMed: 19141867]

82. Butler JM, et al. Endothelial cells are essential for the self-renewal and repopulation of Notchdependent hematopoietic stem cells. Cell stem cell. 2010; 6:251-264. [PubMed: 20207228]

83. Li N, et al. Human umbilical vein endothelial cells increase ex vivo expansion of human CD34(+) PBPC through IL-6 secretion. Cytotherapy. 2006; 8:335-342. [PubMed: 16923609]

84. Yildirim S, et al. Expansion of cord blood CD34+ hematopoietic progenitor cells in coculture with autologous umbilical vein endothelial cells (HUVEC) is superior to cytokine-supplemented liquid culture. Bone marrow transplantation. 2005; 36:71-79. [PubMed: 15895114]

85. Chute JP, et al. Ex vivo culture with human brain endothelial cells increases the SCID-repopulating capacity of adult human bone marrow. Blood. 2002; 100:4433-4439. [PubMed: 12393435]

86. Chute JP, et al. Soluble factors elaborated by human brain endothelial cells induce the concomitant expansion of purified human BM CD34+CD38- cells and SCID-repopulating cells. Blood. 2005; 105:576-583. [PubMed: 15345596]

87. Li B, et al. Endothelial cells mediate the regeneration of hematopoietic stem cells. Stem cell research. 2010; 4:17-24. [PubMed: 19720572]

88. Himburg HA, et al. Pleiotrophin regulates the expansion and regeneration of hematopoietic stem cells. Nature medicine. 2010; 16:475-482.

89. Doan PL, et al. Epidermal growth factor regulates hematopoietic regeneration after radiation injury. Nature medicine. 2013; 19:295-304.

90. Zhou BO, Ding L, Morrison SJ. Hematopoietic stem and progenitor cells regulate the regeneration of their niche by secreting Angiopoietin-1. eLife. 2015; 4:e05521. [PubMed: 25821987]

91. Li W, et al. Primary endothelial cells isolated from the yolk sac and para-aortic splanchnopleura support the expansion of adult marrow stem cells in vitro. Blood. 2003; 102:4345-4353. [PubMed: 12893772] 
92. Ohneda O, et al. Hematopoietic stem cell maintenance and differentiation are supported by embryonic aorta-gonad-mesonephros region-derived endothelium. Blood. 1998; 92:908-919. [PubMed: 9680359]

93. Li W, et al. Hematopoietic stem cell repopulating ability can be maintained in vitro by some primary endothelial cells. Experimental hematology. 2004; 32:1226-1237. [PubMed: 15588947]

94. Yao L, et al. Bone marrow dysfunction in mice lacking the cytokine receptor gp130 in endothelial cells. Blood. 2005; 106:4093-4101. [PubMed: 16118327]

95. Ding L, et al. Endothelial and perivascular cells maintain haematopoietic stem cells. Nature. 2012; 481:457-462. [PubMed: 22281595]

96. Greenbaum A, et al. CXCL12 in early mesenchymal progenitors is required for haematopoietic stem-cell maintenance. Nature. 2013; 495:227-230. [PubMed: 23434756]

97. Aird WC. Phenotypic heterogeneity of the endothelium: II. Representative vascular beds. Circulation research. 2007; 100:174-190. [PubMed: 17272819]

98. Aird WC. Phenotypic heterogeneity of the endothelium: I. Structure, function, and mechanisms. Circulation research. 2007; 100:158-173. [PubMed: 17272818]

99. Birbrair A, Delbono O. Pericytes are Essential for Skeletal Muscle Formation. Stem cell reviews. 2015; 11:547-548. [PubMed: 25896402]

100. Birbrair A, et al. Type-1 pericytes accumulate after tissue injury and produce collagen in an organ-dependent manner. Stem cell research \& therapy. 2014; 5:122. [PubMed: 25376879]

101. Birbrair A, et al. Pericytes at the intersection between tissue regeneration and pathology. Clin Sci (Lond). 2015; 128:81-93. [PubMed: 25236972]

102. Birbrair A, et al. Type- 2 pericytes participate in normal and tumoral angiogenesis. American journal of physiology. Cell physiology. 2014; 307:C25-38. [PubMed: 24788248]

103. Birbrair A, et al. Role of pericytes in skeletal muscle regeneration and fat accumulation. Stem cells and development. 2013; 22:2298-2314. [PubMed: 23517218]

104. Birbrair A, et al. Type-1 pericytes participate in fibrous tissue deposition in aged skeletal muscle. American journal of physiology. Cell physiology. 2013; 305:C1098-1113. [PubMed: 24067916]

105. Birbrair A, et al. Skeletal muscle pericyte subtypes differ in their differentiation potential. Stem cell research. 2013; 10:67-84. [PubMed: 23128780]

106. Birbrair A, et al. Pericytes: multitasking cells in the regeneration of injured, diseased, and aged skeletal muscle. Frontiers in aging neuroscience. 2014; 6:245. [PubMed: 25278877]

107. Sacchetti B, et al. Self-renewing osteoprogenitors in bone marrow sinusoids can organize a hematopoietic microenvironment. Cell. 2007; 131:324-336. [PubMed: 17956733]

108. Pinho S, et al. PDGFRalpha and CD51 mark human nestin+ sphere-forming mesenchymal stem cells capable of hematopoietic progenitor cell expansion. The Journal of experimental medicine. 2013; 210:1351-1367. [PubMed: 23776077]

109. Omatsu Y, et al. Foxc1 is a critical regulator of haematopoietic stem/progenitor cell niche formation. Nature. 2014; 508:536-540. [PubMed: 24590069]

110. Morikawa $S$, et al. Development of mesenchymal stem cells partially originate from the neural crest. Biochemical and biophysical research communications. 2009; 379:1114-1119. [PubMed: 19161980]

111. Morikawa S, et al. Prospective identification, isolation, and systemic transplantation of multipotent mesenchymal stem cells in murine bone marrow. The Journal of experimental medicine. 2009; 206:2483-2496. [PubMed: 19841085]

112. Kopp HG, et al. The bone marrow vascular niche: home of HSC differentiation and mobilization. Physiology. 2005; 20:349-356. [PubMed: 16174874]

113. Gimble JM, Nuttall ME. Bone and fat: old questions, new insights. Endocrine. 2004; 23:183-188. [PubMed: 15146099]

114. Krings A, et al. Bone marrow fat has brown adipose tissue characteristics, which are attenuated with aging and diabetes. Bone. 2012; 50:546-552. [PubMed: 21723971]

115. Fazeli PK, et al. Marrow fat and bone-new perspectives. The Journal of clinical endocrinology and metabolism. 2013; 98:935-945. [PubMed: 23393168] 
116. Abella E, et al. Bone marrow changes in anorexia nervosa are correlated with the amount of weight loss and not with other clinical findings. American journal of clinical pathology. 2002; 118:582-588. [PubMed: 12375646]

117. Cohen A, et al. Increased marrow adiposity in premenopausal women with idiopathic osteoporosis. The Journal of clinical endocrinology and metabolism. 2012; 97:2782-2791. [PubMed: 22701013]

118. Gimble JM. The function of adipocytes in the bone marrow stroma. The New biologist. 1990; 2:304-312. [PubMed: 2288904]

119. Kawai M, de Paula FJ, Rosen CJ. New insights into osteoporosis: the bone-fat connection. Journal of internal medicine. 2012; 272:317-329. [PubMed: 22702419]

120. Poloni A, et al. Molecular and functional characterization of human bone marrow adipocytes. Experimental hematology. 2013; 41:558-566 e552. [PubMed: 23435314]

121. Liu LF, et al. Characterization of age-related gene expression profiling in bone marrow and epididymal adipocytes. BMC genomics. 2011; 12:212. [PubMed: 21545734]

122. Devlin MJ, et al. Caloric restriction leads to high marrow adiposity and low bone mass in growing mice. Journal of bone and mineral research : the official journal of the American Society for Bone and Mineral Research. 2010; 25:2078-2088.

123. Griffith JF, et al. Bone marrow fat content in the elderly: a reversal of sex difference seen in younger subjects. Journal of magnetic resonance imaging : JMRI. 2012; 36:225-230. [PubMed: 22337076]

124. Rosen CJ, et al. Marrow fat and the bone microenvironment: developmental, functional, and pathological implications. Critical reviews in eukaryotic gene expression. 2009; 19:109-124. [PubMed: 19392647]

125. Lecka-Czernik B, Rosen CJ, Kawai M. Skeletal aging and the adipocyte program: New insights from an "old" molecule. Cell cycle. 2010; 9:3648-3654. [PubMed: 20890120]

126. Ogawa T, Kitagawa M, Hirokawa K. Age-related changes of human bone marrow: a histometric estimation of proliferative cells, apoptotic cells, T cells, B cells and macrophages. Mechanisms of ageing and development. 2000; 117:57-68. [PubMed: 10958923]

127. Cao JJ, Sun L, Gao H. Diet-induced obesity alters bone remodeling leading to decreased femoral trabecular bone mass in mice. Annals of the New York Academy of Sciences. 2010; 1192:292297. [PubMed: 20392249]

128. Halade GV, et al. High fat diet-induced animal model of age-associated obesity and osteoporosis. The Journal of nutritional biochemistry. 2010; 21:1162-1169. [PubMed: 20149618]

129. Halade GV, et al. Obesity-mediated inflammatory microenvironment stimulates osteoclastogenesis and bone loss in mice. Experimental gerontology. 2011; 46:43-52. [PubMed: 20923699]

130. Trottier MD, et al. Enhancement of hematopoiesis and lymphopoiesis in diet-induced obese mice. Proceedings of the National Academy of Sciences of the United States of America. 2012; 109:7622-7629. [PubMed: 22538809]

131. Laharrague $\mathrm{P}$, et al. Inflammatory/haematopoietic cytokine production by human bone marrow adipocytes. European cytokine network. 2000; 11:634-639. [PubMed: 11125307]

132. Claycombe K, King LE, Fraker PJ. A role for leptin in sustaining lymphopoiesis and myelopoiesis. Proceedings of the National Academy of Sciences of the United States of America. 2008; 105:2017-2021. [PubMed: 18250302]

133. Chitteti BR, et al. Impact of interactions of cellular components of the bone marrow microenvironment on hematopoietic stem and progenitor cell function. Blood. 2010; 115:32393248. [PubMed: 20154218]

134. Spindler TJ, et al. Adipocytic cells augment the support of primitive hematopoietic cells in vitro but have no effect in the bone marrow niche under homeostatic conditions. Stem cells and development. 2014; 23:434-441. [PubMed: 24083324]

135. Corre $\mathrm{J}$, et al. Human bone marrow adipocytes support complete myeloid and lymphoid differentiation from human CD34 cells. British journal of haematology. 2004; 127:344-347. [PubMed: 15491297] 
136. Naveiras $\mathrm{O}$, et al. Bone-marrow adipocytes as negative regulators of the haematopoietic microenvironment. Nature. 2009; 460:259-263. [PubMed: 19516257]

137. Yokota T, et al. Adiponectin, a new member of the family of soluble defense collagens, negatively regulates the growth of myelomonocytic progenitors and the functions of macrophages. Blood. 2000; 96:1723-1732. [PubMed: 10961870]

138. Touw I, Lowenberg B. No stimulative effect of adipocytes on hematopoiesis in long-term human bone marrow cultures. Blood. 1983; 61:770-774. [PubMed: 6831041]

139. Gimble JM, Nuttall ME. The relationship between adipose tissue and bone metabolism. Clinical biochemistry. 2012; 45:874-879. [PubMed: 22429519]

140. Lecka-Czernik B. Marrow fat metabolism is linked to the systemic energy metabolism. Bone. 2012; 50:534-539. [PubMed: 21757043]

141. Zhu RJ, et al. Hematopoietic recovery following chemotherapy is improved by BADGE-induced inhibition of adipogenesis. International journal of hematology. 2013; 97:58-72. [PubMed: 23264188]

142. Belaid-Choucair Z, et al. Human bone marrow adipocytes block granulopoiesis through neuropilin-1-induced granulocyte colony-stimulating factor inhibition. Stem cells. 2008; 26:1556-1564. [PubMed: 18388301]

143. Miharada K, et al. Lipocalin 2-mediated growth suppression is evident in human erythroid and monocyte/macrophage lineage cells. Journal of cellular physiology. 2008; 215:526-537. [PubMed: 18064607]

144. DiMascio L, et al. Identification of adiponectin as a novel hemopoietic stem cell growth factor. Journal of immunology. 2007; 178:3511-3520.

145. Hotamisligil GS, Shargill NS, Spiegelman BM. Adipose expression of tumor necrosis factoralpha: direct role in obesity-linked insulin resistance. Science. 1993; 259:87-91. [PubMed: 7678183]

146. Calvo W, Forteza-Vila J. Schwann cells of the bone marrow. Blood. 1970; 36:180-188. [PubMed: 5427453]

147. Castaneda-Corral G, et al. The majority of myelinated and unmyelinated sensory nerve fibers that innervate bone express the tropomyosin receptor kinase A. Neuroscience. 2011; 178:196-207. [PubMed: 21277945]

148. Son YJ, Thompson WJ. Schwann cell processes guide regeneration of peripheral axons. Neuron. 1995; 14:125-132. [PubMed: 7826630]

149. Hoke A. Mechanisms of Disease: what factors limit the success of peripheral nerve regeneration in humans? Nature clinical practice. Neurology. 2006; 2:448-454. [PubMed: 16932603]

150. Gordon T. Neurotrophic factor expression in denervated motor and sensory Schwann cells: relevance to specificity of peripheral nerve regeneration. Experimental neurology. 2014; 254:99108. [PubMed: 24468476]

151. Ozaki A, et al. Expression of cytokines and cytokine receptors in human Schwann cells. Neuroreport. 2008; 19:31-35. [PubMed: 18281888]

152. Yamazaki S, et al. Nonmyelinating Schwann cells maintain hematopoietic stem cell hibernation in the bone marrow niche. Cell. 2011; 147:1146-1158. [PubMed: 22118468]

153. Mendez-Ferrer S, et al. Haematopoietic stem cell release is regulated by circadian oscillations. Nature. 2008; 452:442-447. [PubMed: 18256599]

154. Ciurea SO, et al. Pivotal contributions of megakaryocytes to the biology of idiopathic myelofibrosis. Blood. 2007; 110:986-993. [PubMed: 17473062]

155. Yamazaki K, Allen TD. Ultrastructural morphometric study of efferent nerve terminals on murine bone marrow stromal cells, and the recognition of a novel anatomical unit: the "neuro-reticular complex". The American journal of anatomy. 1990; 187:261-276. [PubMed: 2321559]

156. Zhou BO, et al. Leptin-receptor-expressing mesenchymal stromal cells represent the main source of bone formed by adult bone marrow. Cell stem cell. 2014; 15:154-168. [PubMed: 24953181]

157. Hanoun M, et al. Neural Regulation of Hematopoiesis, Inflammation, and Cancer. Neuron. 2015; 86:360-373. [PubMed: 25905810] 
158. Boulais PE, Frenette PS. Making sense of hematopoietic stem cell niches. Blood. 2015; 125:2621-2629. [PubMed: 25762174]

159. Kalinkovich A, et al. Blood-forming stem cells are nervous: direct and indirect regulation of immature human CD34+ cells by the nervous system. Brain, behavior, and immunity. 2009; 23:1059-1065.

160. Afan AM, et al. Bone marrow innervation regulates cellular retention in the murine haemopoietic system. British journal of haematology. 1997; 98:569-577. [PubMed: 9332309]

161. Lucas D, et al. Chemotherapy-induced bone marrow nerve injury impairs hematopoietic regeneration. Nature medicine. 2013; 19:695-703.

162. Scheiermann $\mathrm{C}$, et al. Adrenergic nerves govern circadian leukocyte recruitment to tissues. Immunity. 2012; 37:290-301. [PubMed: 22863835]

163. Scheiermann C, Kunisaki Y, Frenette PS. Circadian control of the immune system. Nature reviews. Immunology. 2013; 13:190-198.

164. Haus E, et al. Chronobiology in hematology and immunology. The American journal of anatomy. 1983; 168:467-517. [PubMed: 6364772]

165. Haus E, Smolensky MH. Biologic rhythms in the immune system. Chronobiology international. 1999; 16:581-622. [PubMed: 10513884]

166. Lucas D, et al. Mobilized hematopoietic stem cell yield depends on species-specific circadian timing. Cell stem cell. 2008; 3:364-366. [PubMed: 18940728]

167. Hanoun M, et al. Acute myelogenous leukemia-induced sympathetic neuropathy promotes malignancy in an altered hematopoietic stem cell niche. Cell stem cell. 2014; 15:365-375. [PubMed: 25017722]

168. Arranz L, et al. Neuropathy of haematopoietic stem cell niche is essential for myeloproliferative neoplasms. Nature. 2014; 512:78-81. [PubMed: 25043017]

169. Spiegel A, et al. Catecholaminergic neurotransmitters regulate migration and repopulation of immature human CD34+ cells through Wnt signaling. Nature immunology. 2007; 8:1123-1131. [PubMed: 17828268]

170. Fitch SR, et al. Signaling from the sympathetic nervous system regulates hematopoietic stem cell emergence during embryogenesis. Cell stem cell. 2012; 11:554-566. [PubMed: 23040481]

171. Alexander KA, et al. Osteal macrophages promote in vivo intramembranous bone healing in a mouse tibial injury model. Journal of bone and mineral research : the official journal of the American Society for Bone and Mineral Research. 2011; 26:1517-1532.

172. Chang MK, et al. Osteal tissue macrophages are intercalated throughout human and mouse bone lining tissues and regulate osteoblast function in vitro and in vivo. Journal of immunology. 2008; 181:1232-1244.

173. Pettit AR, et al. Osteal macrophages: a new twist on coupling during bone dynamics. Bone. 2008; 43:976-982. [PubMed: 18835590]

174. Winkler IG, et al. Bone marrow macrophages maintain hematopoietic stem cell (HSC) niches and their depletion mobilizes HSCs. Blood. 2010; 116:4815-4828. [PubMed: 20713966]

175. Chow A, et al. Bone marrow CD169+ macrophages promote the retention of hematopoietic stem and progenitor cells in the mesenchymal stem cell niche. The Journal of experimental medicine. 2011; 208:261-271. [PubMed: 21282381]

176. Christopher MJ, et al. Expression of the G-CSF receptor in monocytic cells is sufficient to mediate hematopoietic progenitor mobilization by G-CSF in mice. The Journal of experimental medicine. 2011; 208:251-260. [PubMed: 21282380]

177. Albiero M, et al. Bone Marrow Macrophages Contribute to Diabetic Stem Cell Mobilopathy by Producing Oncostatin M. Diabetes. 2015; 64:2957-2968. [PubMed: 25804939]

178. Williams DA, et al. Fibronectin and VLA-4 in haematopoietic stem cell-microenvironment interactions. Nature. 1991; 352:438-441. [PubMed: 1861722]

179. Scott LM, Priestley GV, Papayannopoulou T. Deletion of alpha4 integrins from adult hematopoietic cells reveals roles in homeostasis, regeneration, and homing. Molecular and cellular biology. 2003; 23:9349-9360. [PubMed: 14645544] 
180. Dutta P, et al. Myocardial infarction accelerates atherosclerosis. Nature. 2012; 487:325-329. [PubMed: 22763456]

181. Dutta P, et al. Macrophages retain hematopoietic stem cells in the spleen via VCAM-1. The Journal of experimental medicine. 2015; 212:497-512. [PubMed: 25800955]

182. Ludin A, et al. Monocytes-macrophages that express alpha-smooth muscle actin preserve primitive hematopoietic cells in the bone marrow. Nature immunology. 2012; 13:1072-1082. [PubMed: 22983360]

183. Hoggatt J, et al. Prostaglandin E2 enhances hematopoietic stem cell homing, survival, and proliferation. Blood. 2009; 113:5444-5455. [PubMed: 19324903]

184. Casanova-Acebes M, et al. Rhythmic modulation of the hematopoietic niche through neutrophil clearance. Cell. 2013; 153:1025-1035. [PubMed: 23706740]

185. Wheway $\mathrm{J}$, et al. A fundamental bimodal role for neuropeptide $\mathrm{Y} 1$ receptor in the immune system. The Journal of experimental medicine. 2005; 202:1527-1538. [PubMed: 16330815]

186. Kuo LE, et al. Neuropeptide $Y$ acts directly in the periphery on fat tissue and mediates stressinduced obesity and metabolic syndrome. Nature medicine. 2007; 13:803-811.

187. Lee NJ, Herzog H. NPY regulation of bone remodelling. Neuropeptides. 2009; 43:457-463. [PubMed: 19748118]

188. Park MH, et al. Neuropeptide Y regulates the hematopoietic stem cell microenvironment and prevents nerve injury in the bone marrow. The EMBO journal. 2015; 34:1648-1660. [PubMed: 25916827]

189. Manwani D, Bieker JJ. The erythroblastic island. Current topics in developmental biology. 2008; 82:23-53. [PubMed: 18282516]

190. Boyle WJ, Simonet WS, Lacey DL. Osteoclast differentiation and activation. Nature. 2003; 423:337-342. [PubMed: 12748652]

191. Kollet O, et al. Osteoclasts degrade endosteal components and promote mobilization of hematopoietic progenitor cells. Nature medicine. 2006; 12:657-664.

192. Balooch G, et al. TGF-beta regulates the mechanical properties and composition of bone matrix. Proceedings of the National Academy of Sciences of the United States of America. 2005; 102:18813-18818. [PubMed: 16354837]

193. Lymperi S, et al. Inhibition of osteoclast function reduces hematopoietic stem cell numbers in vivo. Blood. 2011; 117:1540-1549. [PubMed: 21131587]

194. Mansour A, et al. Osteoclasts promote the formation of hematopoietic stem cell niches in the bone marrow. The Journal of experimental medicine. 2012; 209:537-549. [PubMed: 22351931]

195. Nakamura-Ishizu A, et al. Megakaryocytes are essential for HSC quiescence through the production of thrombopoietin. Biochemical and biophysical research communications. 2014; 454:353-357. [PubMed: 25451253]

196. Heazlewood SY, et al. Megakaryocytes co-localise with hemopoietic stem cells and release cytokines that up-regulate stem cell proliferation. Stem cell research. 2013; 11:782-792. [PubMed: 23792434]

197. Kacena MA, Gundberg CM, Horowitz MC. A reciprocal regulatory interaction between megakaryocytes, bone cells, and hematopoietic stem cells. Bone. 2006; 39:978-984. [PubMed: 16860008]

198. Olson TS, et al. Megakaryocytes promote murine osteoblastic HSC niche expansion and stem cell engraftment after radioablative conditioning. Blood. 2013; 121:5238-5249. [PubMed: 23667055]

199. Soderberg SS, Karlsson G, Karlsson S. Complex and context dependent regulation of hematopoiesis by TGF-beta superfamily signaling. Annals of the New York Academy of Sciences. 2009; 1176:55-69. [PubMed: 19796233]

200. Mercier FE, Ragu C, Scadden DT. The bone marrow at the crossroads of blood and immunity. Nature reviews. Immunology. 2012; 12:49-60.

201. Barlozzari T, Herberman RB, Reynolds CW. Inhibition of pluripotent hematopoietic stem cells of bone marrow by large granular lymphocytes. Proceedings of the National Academy of Sciences of the United States of America. 1987; 84:7691-7695. [PubMed: 3478719] 
202. Degliantoni G, et al. Natural killer (NK) cell-derived hematopoietic colony-inhibiting activity and NK cytotoxic factor. Relationship with tumor necrosis factor and synergism with immune interferon. The Journal of experimental medicine. 1985; 162:1512-1530. [PubMed: 3932579]

203. Sharara LI, et al. Deregulated TCR alpha beta T cell population provokes extramedullary hematopoiesis in mice deficient in the common gamma chain. European journal of immunology. 1997; 27:990-998. [PubMed: 9130655]

204. Monteiro JP, et al. Normal hematopoiesis is maintained by activated bone marrow CD4+ T cells. Blood. 2005; 105:1484-1491. [PubMed: 15514013]

205. Zeng D, et al. Unique patterns of surface receptors, cytokine secretion, and immune functions distinguish $\mathrm{T}$ cells in the bone marrow from those in the periphery: impact on allogeneic bone marrow transplantation. Blood. 2002; 99:1449-1457. [PubMed: 11830499]

206. Price PW, Cerny J. Characterization of CD4+ T cells in mouse bone marrow. I. Increased activated/memory phenotype and altered TCR Vbeta repertoire. European journal of immunology. 1999; 29:1051-1056. [PubMed: 10092110]

207. Urbieta M, et al. Hematopoietic progenitor cell regulation by CD4+CD25+ T cells. Blood. 2010; 115:4934-4943. [PubMed: 20200356]

208. Fujisaki J, et al. In vivo imaging of Treg cells providing immune privilege to the haematopoietic stem-cell niche. Nature. 2011; 474:216-219. [PubMed: 21654805]

209. Summers C, et al. Neutrophil kinetics in health and disease. Trends in immunology. 2010; 31:318-324. [PubMed: 20620114]

210. Furze RC, Rankin SM. Neutrophil mobilization and clearance in the bone marrow. Immunology. 2008; 125:281-288. [PubMed: 19128361]

211. Petit I, et al. G-CSF induces stem cell mobilization by decreasing bone marrow SDF-1 and upregulating CXCR4. Nature immunology. 2002; 3:687-694. [PubMed: 12068293]

212. Valenzuela-Fernandez A, et al. Leukocyte elastase negatively regulates Stromal cell-derived factor-1 (SDF-1)/CXCR4 binding and functions by amino-terminal processing of SDF-1 and CXCR4. The Journal of biological chemistry. 2002; 277:15677-15689. [PubMed: 11867624]

213. Levesque JP, et al. Vascular cell adhesion molecule-1 (CD106) is cleaved by neutrophil proteases in the bone marrow following hematopoietic progenitor cell mobilization by granulocyte colonystimulating factor. Blood. 2001; 98:1289-1297. [PubMed: 11520773]

214. Levesque JP, et al. Granulocyte colony-stimulating factor induces the release in the bone marrow of proteases that cleave c-KIT receptor (CD117) from the surface of hematopoietic progenitor cells. Experimental hematology. 2003; 31:109-117. [PubMed: 12591275]

215. Heissig B, et al. Recruitment of stem and progenitor cells from the bone marrow niche requires MMP-9 mediated release of kit-ligand. Cell. 2002; 109:625-637. [PubMed: 12062105]

216. Levesque JP, et al. Characterization of hematopoietic progenitor mobilization in protease-deficient mice. Blood. 2004; 104:65-72. [PubMed: 15010367]

217. Singh P, et al. Expansion of bone marrow neutrophils following G-CSF administration in mice results in osteolineage cell apoptosis and mobilization of hematopoietic stem and progenitor cells. Leukemia. 2012; 26:2375-2383. [PubMed: 22543963]

218. Eash KJ, et al. CXCR4 is a key regulator of neutrophil release from the bone marrow under basal and stress granulopoiesis conditions. Blood. 2009; 113:4711-4719. [PubMed: 19264920]

219. Poulos MG, et al. Endothelial Jagged-1 is necessary for homeostatic and regenerative hematopoiesis. Cell reports. 2013; 4:1022-1034. [PubMed: 24012753] 


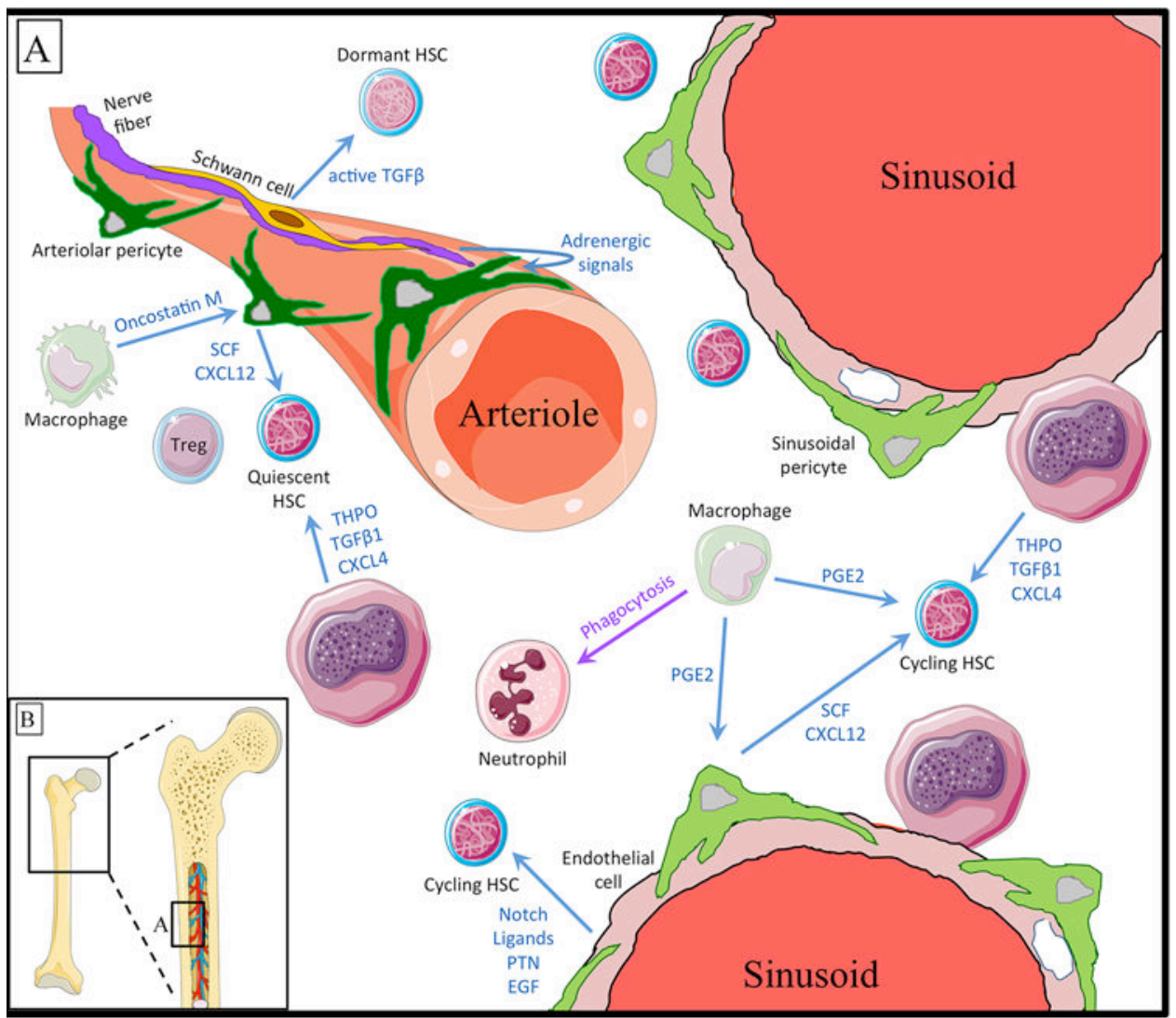

Figure 1.

Diagram illustrating the quiescent arteriolar and the active sinusoidal HSC niches during BM homeostasis. The BM microenvironment hosts various hematopoietic and nonhematopoietic cell types, including macrophages, megakaryocytes, lymphocytes, neutrophils, pericytes, and endothelial and Schwann cells. These cells contribute to the BM microenvironment and regulate HSCs directly by secretion of cytokines such as CXCL12 and SCF and/or indirectly through signaling via other cells, for example, by prostaglandin E2, which increases the expression of CXCL12 in perivascular cells. Deeply quiescent (dormant) HSCs are found around arterioles, while activated HSCs, which are significantly more abundant than dormant HSCs, are located near sinusoids. TGF $\beta$, transforming growth factor $\beta$; THPO, thrombopoietin; PTN, pleiotrophin; PGE2, prostaglandin E2; EGF, epidermal growth factor; $\mathrm{T}_{\text {reg }}, \mathrm{CD}^{+}{ }^{+} \mathrm{CD} 25^{+} \mathrm{FOXP} 3^{+}$regulatory $\mathrm{T}$ cell. 